\title{
On Linguistic Philosophy of Mikhail Bakhtin and Hallidayan Systemic Functional Linguistics
}

\author{
Hang Zou \\ School of Foreign Languages, East China Normal University, Shanghai, China; \\ School of Foreign Languages, Jiangsu University, Zhenjiang, Jiangsu Province, China
}

\begin{abstract}
It is noteworthy that florid descriptions of interaction between linguistics and the philosophy of language are regularly inspired. In this paper, parallels have been drawn between Bakhtin's philosophical perspectives and Hallidayan theoretical claims of Systemic Functional Linguistics (SFL). Through the analysis of Bakhtin's theory of dialogism, heteroglossia, chronotope and metalinguistics, I argue that Hallidayan Systemic Functional Linguistic theory is compatible with Bakhtin's philosophical perspectives to a great extent in terms of the close relations between speech genre and register, heteroglossia and appraisal theory as well as metalinguistics and metafunctions. It is safe to say that as a precursor, Bakhtin has a profound influence on socio-semioticians like Halliday who has expounded in linguistics.
\end{abstract}

Index Terms-Systemic Functional Linguistics, dialogism, heteroglossia, appraisal theory, metafunctions

\section{INTRODUCTION}

Mikhail Bakhtin, who a decade ago was a distinguished Russian philosopher, literary critic, semiotician and scholar whose work has influential within the fields of linguistic philosophy, literary theory, philosophy of language, humanities methodology and many other disciplines having huge influence on linguistics as a whole. It is worth noting that language for Bakhtin is both a cognitive and social practice and he is primarily interested in concrete utterances and the dialogic relations into which they enter. It comes as no surprise, therefore, that Bakhtin has proved attractive to language researchers who have adopted functional descriptive framework for a number of studies in linguistics. In the following part, it would be better to show than tell something about Bakhtin's philosophical perspectives shedding light on language and linguistic studies.

\section{Linguistic PhiLOSOPHY OF MikHAil BaKhtin}

Bakhtin is not first and foremost a linguist, instead his sphere of interest is often characterized as philosophical anthropology including all basic forms of human activities. When advancing his idea about language and language use, Bakhtin was much ahead of his time with most of his observations assuming an enormous importance for linguistics, especially to those who interested in pragmatics. His main philosophical perspectives are illustrated as follows in sufficient detail.

\section{A. Dialogism}

Dialogism, which is of crucial importance to Bakhtin $(1981,1986)$ is a term to elucidate the interactions between a speaker's words, or utterances, and the relationship they enter into with the utterances of other speakers, which owns implications for the way to understand oral or written communication. The meaning of dialogism lies not only in the interactions between speakers and listeners but in other fields, other genre, being perceived in Bakhtin's own work. As a reflection of this, the fields of linguistics, literary criticism and philosophy, for example, all can enter into dialogue with each other and interanimate one another. Suffice it to say that being considered as a universal form of human communication and with its emphasis on context which can be conceived of as the information surrounding the information, Bakhtin's dialogism attempts to dissolve traditional oppositions of "the individual to society, of self to other, of the specific utterance to the totality of language, and of particular actions to the world of norms and conventions" (Morson, 1986, p.11). This assumption is related to the fact that the voices-saturated dialogical work serves to recognize the multiplicity of perspectives and voices and represents the reality of language-use. To recapitulate, the dialogism is idiosyncratic in having a combative quality in that it is always in an intense relationship with another's world, with word being addressed to a listener and anticipating a response.

\section{B. Heteroglossia/Intertextuality}

It is illustrative to know that the term intertextuality appeared nowhere in Bakhtin's work, instead, it was coined and expounded by Julia Kristeva(1981) in her work: Desire in Language: A Semiotic Approach to Literature and Art. In the view of Kristeva, intertextuality is a mechanism to connect both ourselves and social text with which we write ourselves into the social text and also reflects the social factors shaping us. Being reframed by Kristeva as 'intertextuality', Bakhtin's theory of heteroglossia is well recapitulated by his quotation: "Each word tastes of a context and contexts in 
which it has lived its socially charged life; all words and forms are populated by intentions" (Bakhtin, 1981, p.293). That means language serving as a tool for social practice is always subject to human beings' intents as well as different social evaluations and assumptions and, hence, heteroglossic, therefore, in any very obvious sense, every utterance can be conceived of as half-ours and half-someone else's. Being in contradistinction to the view that language is simply static and nothing but an isolated means to communicate information, Bakhtin believed that language in its very essence is heteroglossic and language-use is mediated by social ways of seeing contested in dialogue. As Bakhtin (1981, p.291) elucidated,

"Thus at any given moment of its historical existence, language is heteroglot from top to bottom: it represents the co-existence of social-ideological contradictions between the present and the past, between differing epochs of the past, between different socio-ideological groups in the present... These 'languages' of heteroglossia intersect each other in a variety of ways, forming new socially typifying 'languages"”.

Bakhtin also illuminated important dimensions of language as social-construction-saturated, with both speaker/writer and listener/reader making meaning, which reflects language's idiosyncrasy of inherently responsive. We need to take cognizance of the fact that understanding is imbued with ideology and stance in that we all permanently immersed in relational reciprocity in which we anticipate and evaluate other's responses and build on our utterances on historic utterances made by others. As Bakhtin (1987) evocatively puts it, our utterances are full of others' words with echoes and reverberations of other utterances with which it is related by the communality of the sphere of speech communication. Hence, rather than being self-sufficient, utterances with echoes and reverberations can mutually reflect one another during the process of communication.

\section{Metalinguistics}

The term metalingvistika ('metalinguistics') was introduced by Bakhtin in his novel 'The problem of text' to cover the study of "concrete forms of texts and concrete conditions of the life of texts, their interrelations, and their interactions" (Bakhtin, 1986, p.114). Bakhtin's metalinguistics as philosophy of language is generally used to study the relations between language and society or culture by emphasizing the collective symbiotic and cultural values of utterance existence. Generally speaking, the most conspicuous point in Bakhtin's view of metalinguistics is its rejection of the monolithic system of structuralisms and its intention of finding repeating features of reality as speech communication and relations among them. Being distinguishable from the linguistic view in which language is considered as an abstract system, the metalinguistic view takes language in use and in concrete context as meaningful. The linguistic-metalinguistic opposition also stimulates the discussion of the differences between units of language, namely, words as well as sentences and units of speech communication, namely, utterances. As Bakhtin (1981) argued,

"An utterance is a finalized whole, guaranteeing the possibility of a response. It is determined by three factors: semantic exhaustiveness of the theme, the speaker's plan or will, and typical compositional and generic forms of finalization. Further, the utterance is related both to the speaker and to the addressee. In contract, units of language, such as words and sentences, have a finality of grammatical form and a finality of meaning that is only abstract: In themselves, they belong to nobody and are addressed to nobody. They are the building blocks of utterances and are typically surrounded by a context of the speech of the same speaker. Thus, we do not exchange sentences but utterances that are built from language units (words, phases, and sentences)."

However, though differences exist, Bakhtin still admits the decisive role of linguistics in that the result of linguistics can be fully utilized by metalinguistics. As a reflection of this, we should on the one hand, embrace the perspective of keeping the notion of sentence and utterance apart and on the other hand, not absolutely reject any view.

\section{Speech Genres}

As one of the central concepts of Bakhtin's philosophy of language, speech genres mean "relatively stable and normative types of utterances developed in different spheres of communication" (Bakhtin, 1986, p.60, 81). That is to say, "utterances have definite and relatively stable typical forms of construction of the whole" (Bakhtin, 1986, p.78). Among the three factors, namely, referential and semantic exhaustiveness of the theme, speaker's motivation and plan, and generic understood forms of language, the last one is most integral. Because even if utterances own the characteristics of being heterogeneous, changeable, and flexible, they have the normative significance for the speaker which are called as speech genres. It is illustrative to know that speech genre serves as an important role in communication. Bakhtin showed amazing insight into the use of speech genres, for example, as he claimed,

"We learn to cast out speech in generic forms and, when hearing other's speech, we argue its genre from the very first word; we predict a certain length and a certain compositional structure; we foresee the end; that is, from the very beginning we have a sense of the speech whole, which is only later differentiated during the speech process. If speech genres did not exist and we had not mastered them, if we had to originate them during the speech process and construct each utterance at will for the first time, speech communication would be almost impossible" (1986, p.78-79).

Bakhtin further claimed the different ranges of speech genres and made it clear that the concept applies both to oral speech but also to written communication. To be clear, speech genres cover from a single word utterance to short and direct commands to everyday communication to literary and rhetorical works among which culture and social situations mean a lot. 


\section{Compatability Between Bakhtin’s Linguistic Philosophy and HaLlidayan Systemic FunCTIONAL} LINGUISTICS

It is of paramount importance to acknowledge the fact that Halliday's deliberations on language are extensive and complex, and span a considerable number of years, and appear in a number of texts. However, one could say that, if there is a general concern that underlies his deliberations, then it is a concern to develop a social-functional model of language which is reflected in Halliday's consideration of why the linguistic resources at hand are patterned into the particular structures manifested in our language (Bek \& Tan, 1999, p.61). Being as an approach to language description, SFL serves the function of modelling linguistic choices in terms of three metafunctions, namely, ideational, interpersonal and textual metafunction. Comparing Bakhtin's linguistic philosophy which was mentioned above and the main theoretical claims of SFL, namely, language use is functional and its functions are to make meaning which is influenced by social and cultural context in which they are exchanged and the process of using language is a semiotic process, a process of making meaning by choosing, I argue that compatability can be found between Hallidayan SFL and Bakhtin's philosophical perspectives in the following aspects.

\section{A. Speech Genres and Register}

As Bakhtin argued, "Language is realised in the form of individual concrete utterances (oral and written) by participants in the various areas of human activity" (Bakhtin 1986, p.60). Utterances are identified as the real units of speech communication which distinguish from the abstract language structures because concrete utterances are used in various situations of human activities determined by different cultural and social factors. In SFL, Halliday fully developed the ideas of Bakhtin's, which is reflected in his concepts of genre and register. By offering a comprehensive account of the nature of language use and text construction, Halliday provided the elucidation of the interrelationships between language, situation and culture which are the three crucial components of a systemic functional theory. The term genre is used to describe the impacts of the context of culture on language, by exploring the staged, step-by-step structure cultures institutionalize as ways of achieving goals, while register theory describes the impact of the immediate context of situation of a language event on the way language is used. (Eggins, 2004, p.9). Within register, there are three variables, namely, the register variable of field which refers to the role language is used to talk about, the register variable of mode which refers to the role language is playing in the interaction and the register variable of tenor which refers to the role relationship between the interactants. Suffice it to say, being traced to the same origin, Halliday's concepts of genre and register are the further development of Bakhtin's linguistic philosophy because they both fully reflect Bakhtin's concepts of dialogism and are useful in explaining how texts are structured according to the interrelationships between language users in different cultural and social contexts. Reasons are illustrated in detail as follows.

Firstly, Halliday's concept of genre is compatible with Bakhtin's which both refer to the relatively stable and normative types of utterances influenced by cultural factors. They all believe that both the textual environment but also the extra-textual context play an important role to the expectancies on which texts depend to make sense, which means texts are expected to display continuity not just with elements within their boundaries, but with the contexts within which they take place. Since the fact that all texts involve indeterminacies of meanings which are an integral feature of the genre, we need to know how to resolve those indeterminacies not only by reference to textual environment but to extra-textual context and capture meaning within the genre. Secondly, the register variable of tenor which emphasizes the social role relationships played by interactants is to a great extent compatible with Bakhtin's dialogism which attaches great emphasis on interaction between speakers. Based on register theory in SFL, instinctively, we can perceive the social role played in different situations having effects on how language is used. As a reflection of this, the general notion of 'role relationship' can be seen as a complex of three simultaneous dimensions, namely, power, contact and affective involvement (Eggins, 2004) among which power dimension positions situations in terms of whether the roles we are playing are equal or not, contact dimension positions situations in terms of whether the roles we are playing are those that bring us into frequent or infrequent contact, and affective involvement dimension refers to the extent to which we are emotionally involved or committed in a situation. Under different circumstances, speakers involved choose different forms of speech by considering both individual stance but also stance relating to others, from both the perspective of self-role in society and the whole world norms and conventions, which is totally in agreement with Bakhtin's language philosophy of dialogism. Therefore, human speech regulated by context of culture (genre) and context of situation(register) is voices-saturated dialogical work which can recognize the multiplicity of perspectives and voices and represents the reality of language-use and during the whole process, it is the configuration of meaning which serves the role of characterizing a register as a text variety, because in SFL, texts are conceived of as instances of linguistic interaction in which speakers engage in operational contexts. What's more, the concept of register arises from a concern with the importance of language in action because in the production of an utterance, context has the function of activating meaning and meaning activates wording. Lastly, since texts can be considered as instances of a register which itself is a midpoint along Halliday's 'cline of instantiation' (Halliday, 2002 [1992]). As Bakhtin, Halliday's cline also resolved Saussure's unnecessary bifurcation of langue and parole for proposing that 'langue and parole are simply different observational positions' and he argued that seen from the instantial end of the cline (of instantiation - authors), 
a register appears as a cluster of similar texts, a text type; whereas seen from the systemic end, a register appears as a subsystem (Halliday, 2005 [1995], p.248).

\section{B. Heteroglossia and Appraisal Theory}

Appraisal theory is concerned with the linguistic resources by which texts or speakers express, negotiate and naturalize particular intersubjective and ideological positions (White, 2015) so as to analyze how speakers or writers value the entities within the text that they produce. As mentioned before, three modes of meaning, namely, ideational, interpersonal and textual are operated simultaneously in utterances and appraisal is located as an interpersonal system at the level of discourse semantics. In appraisal theory, three systems are put forward among which attitude is concerned with ways of feeling, engagement and graduation reflect alignment, solidarity and the construed readers. It is contended that 'attitudinal evaluations are of interest not only because they reveal the speaker's/writer's feelings and values but also because their expression can be related to the speaker's/writer's status or authority as construed by the text, and because they operate rhetorically to construct relations of alignment and rapport between the writer/speaker and actual or potential respondents (Martin \& White, 2005, p.2). Seen from multiple vantage points, appraisal theory is believed to be compatible with Bakhtin's theory of dialogism and heteroglossia for the following reasons.

Firstly, generally speaking, heteroglossia in Bakhtin's view means the stratification of any language into different socio-ideological languages which are forms for conceptualizing specific world view (1981, p.291-292), therefore, linguistic form should be a sign which functions simultaneously in all the diverse areas of social and ideological activities in which people evaluate and communicate things depending on the material contexts. As a reflection of this, SFL emphasizes three kinds of social-functional 'needs' among which the second one being to interact with the social world by negotiating social roles and attitudes conforms to Bakhtin's idea of heteroglossia to a great extent. In the second place, according to Bakhtin, instead of being a neutral medium, language is populated with intentions of others and words are saturated with voice of self as well of others in that texts are idiosyncratic in being invested with an intertextual dimension. In the third place, the subsystems of engagement which emphasize analyzing the relations between speaker/writer and other respondents in heteroglossic settings dealing with sourcing attitudes and the play of voice in discourse are believed to develop influenced by Bakhtin's theory. As Martin and White (2005, p.97) explicate, engagement is related to meanings which in various ways construe for the text a heteroglossic backdrop of prior utterances, alternative viewpoints and anticipated responses. By distinguishing monogloss and heterogloss, the way of sourcing attitudes and the play of voices around opinions in discourse are evaluated. Martin and White also subdivide instances of heteroglossic utterances into "dialogue contract" and "dialogue expand" on the basis of "the degree to which an utterance, by dint of one or more of these locutions actively makes allowances for dialogically alternative positions and voices (dialogic expansion) or alternatively acts to challenge, fend off or restrict the scope of such (dialogic contraction)" (Martin \& White, 2005, p.102). In the engagement subsystem, Martin and White also attached enormous importance to how to choose semantic and lexicogrammatical resources to show someone's own stance as well as the interactions between self and others and between one's owe stance and stance of other expected responders' so as to illustrate the alignment or disalignment relationship, which is with the same essence of dialogism essentially. Thirdly, what matters a lot to Bakhtin is not 'linguistic understanding', and its corresponding generalized meanings, but their subjectification by individuals, therefore, we need to take cognizance of the fact that subjectification is a dynamic process instead of a stable and static one which is more complex illustrated in written texts because the readership is heterogeneous and the text is received within a broad spatio-temporal context. Correspondingly, appraisal theory also stresses the importance of considering meanings not as inherently 'system' properties, but as something generated out of the assumptions and evaluations that are brought to bear in the whole reading process. Furthermore, corresponding to Bakhtin's theory of chronotope, appraisal theory also emphasizes understanding experience whereby temporal and spatial relationships being expressed in language.

\section{Metalinguistics vs Metafunctions}

In the view of Bakhtin, metalinguistics covers the study of concrete forms of texts and concrete conditions of the life of texts as well as their interrelations. Bakhtin's metalinguistics as philosophy of language is generally used to study the relations between language and society or culture by emphasizing the collective symbiotic and cultural values of utterance existence. Being distinguishable from the linguistic view in which language is considered as an abstract system, the metalinguistic view takes language in use in concrete context as meaningful. In SFL, Halliday also identifies three metafunctions of language among which the ideational function serves to reflect situations and events in the objective as well as subjective world with entities, actions and processes involved; the interpersonal metafunction serves to maintain interpersonal relationship and in the textual metafunction ideational and interpersonal meanings are actualized. Being intrinsically linked with Bakhtin's concept of metalinguistics, language in SFL with three metafunctions is functional as it is concerned with the mechanisms of text structure, function and meaning of language. By the same token, human language should be analyzed in social context where a particular lexico-grammatical choice is constructed under the influence of the social and cultural context.

\section{CONCLUSION}


It is safe to say that Bakhtin is the precursor of much of what socio-semioticians like Halliday have expounded in his functional models of language. This paper sums up Bakhtin's main philosophical claims, namely, dialogism, heteroglossia and metalinguistics and compares them with Hallidayan Systemic Functional Linguistic perspectives. To recapitulate, it is pertinent to note that Hallidayan SFL is compatible with linguistic philosophy of Bakhtin to a great extent in terms of the close relation between speech genre and register, heteroglossia and appraisal theory as well as Metalinguistics and metafunctions. It is instructive to know that probing into the philosophical perspectives in linguistics is of paramount importance for linguists in that on the one hand it can deepen our understanding of linguistic theories and on the other hand, serving as the tool of prioritizing the inquiry on the nature of meaning, philosophy of language can investigate how language and meaning relate to truth and the world to a great extent so as to understand the essence of interpersonal communication.

Generalizing on the basis of the discussion above, we can now safely claim that English language teaching pedagogical benefits may also be reaped from the present research, as new insights can be brought into the teaching process, the illumination of the role of teachers in classroom etc. Suffice it to say that, Bakhtin-orientated approach to teaching plays a pivotal role in achieving the right balance between proximity to and distance from students, offering students more opportunities to express themselves and gain access to the world of students easier.

\section{ACKNOWLEDGMENTS}

This work was supported by both the grant from Higher Education Reform Project, Jiangsu University (Grant No. 2015JGYB025) and the grant from Research and Innovation Project for Postgraduate Students, East China Normal University. (Grant No. ykc17052)

\section{REFERENCES}

[1] Bakhtin, M. M. (1981). The dialogic imagination. Austin: University of Texas Press.

[2] Bakhtin, M.M. (1986). Speech genres and other late essays. Austin: University of Texas Press.

[3] Bakhtin, M. M. (1987). Speech genres and other late essays. Austin: University of Texas Press.

[4] Bek, S. \& Tan, S. (1999). Bakhtin and Halliday: A Case of Misrepresentation. Dialogism: An International Journal of Bakhtin Studies, 99(2), pp. 60-86.

[5] Braxley, K. (2005). Mastering academic English: International graduate students' use of dialogue and speech genres to meet the writing demands of graduate school. In J. K. Hall, G. Vitanova \& L. Marchenkova (eds.) Dialogue with Bakhtin on second and foreign language learning. Mahwah: NJ : Lawrence Erlbaum, pp. 11-32.

[6] Eggins, S. (2004). An introduction to systemic functional linguistics. New York. London: Continuum.

[7] Halliday, M. A. K. ([2002] 1992). How do you mean? In J. J. Webster (ed.) On Grammar. Volume 1 in Collected Works of M. A. K. Halliday. London and New York: Continuum, pp. 352-368.

[8] Halliday, M. A. K. (2005 [1995]). Computing meanings: Some reflections on past experience and present prospects. In J. J. Webster (ed.) Computational and Quantitative Studies. Volume 6 in the Collected Works of M. A. K. Halliday. London and New York: Continuum, pp. 239-267.

[9] Kristeva, J. (1981). Desire in Language: A Semiotic Approach to Literature and Art. Michigan: Wayne State University Press.

[10] Martin, J. R., \& White, P. R. (2005). The language of evaluation. Appraisal in English. New York: Palgrave.

[11] Morson, G. S. (1986). Preface: Perhaps Bakhtin. In G.S. Morson (Ed.), Bakhtin: Essays and Dialogues on His Work. Chicago: University of Chicago Press.

[12] White, P. (2015). Introductory tour through appraisal theory. Retrieved June 15, 2016, from http://www.grammatics.com/appraisal/index.html.

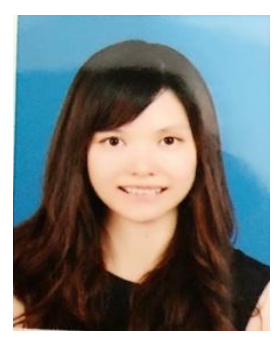

Hang Zou received the M. A. degree in TESOL international from Monash University, Melbourne, Australia in 2009. She is currently the Ph.D. candidate in East China Normal University and also a lecturer with the School of Foreign Languages, Jiangsu University, Zhenjiang, Jiangsu Province, China. Her research fields include Systemic Functional Linguistics, construction grammar, academic discourse analysis. 